\title{
Forbidding your cake and eating it too: health performance strategies in U.S. middle class families
}

\author{
Laurel Graham ${ }^{1} \cdot$ Jennifer Friedman ${ }^{1} \cdot$ Xamil Vega $^{2}$
}

Accepted: 7 February 2021 / Published online: 8 March 2021

(C) The Author(s), under exclusive licence to Springer Nature Limited part of Springer Nature 2021

\begin{abstract}
Interviewing 67 primarily middle-class parents and children in a southern U.S. city, we learned that families know a great deal about the dangers of excess sugar consumption. However, in the private spaces of family life, families let down their guard and enjoy sugary treats, often treating them as symbolic markers of love and comfort. Theoretical concepts emerging from the dramaturgical perspective of Erving Goffman (1959) and from contemporary symbolic interactionists illuminate how sugar consumption is simultaneously shunned and celebrated in private family life. Moving beyond previous research, we track the ways sugary products facilitate love, sanity, and privacy to make daily family life bearable for both parents and children. We call the rhetorical and physical practices that enable excusable sugar indulgence Health Performance Strategies. Our findings on how families engage in these health performance strategies have broader implications for many other efforts to govern the health habits of families.
\end{abstract}

Keywords Sugar · Family · Children · Goffman · Interaction · Consumer culture

Laurel Graham

Lgraham2@usf.edu

1 Department of Sociology, University of South Florida, 4202 E Fowler Ave. CPR 107, Tampa, FL 33620, USA

2 Knight's College of Medicine, University of Central Florida, 6850 Lake Nona Blvd, Orlando, FL 32827, USA 


\section{Plate 1}

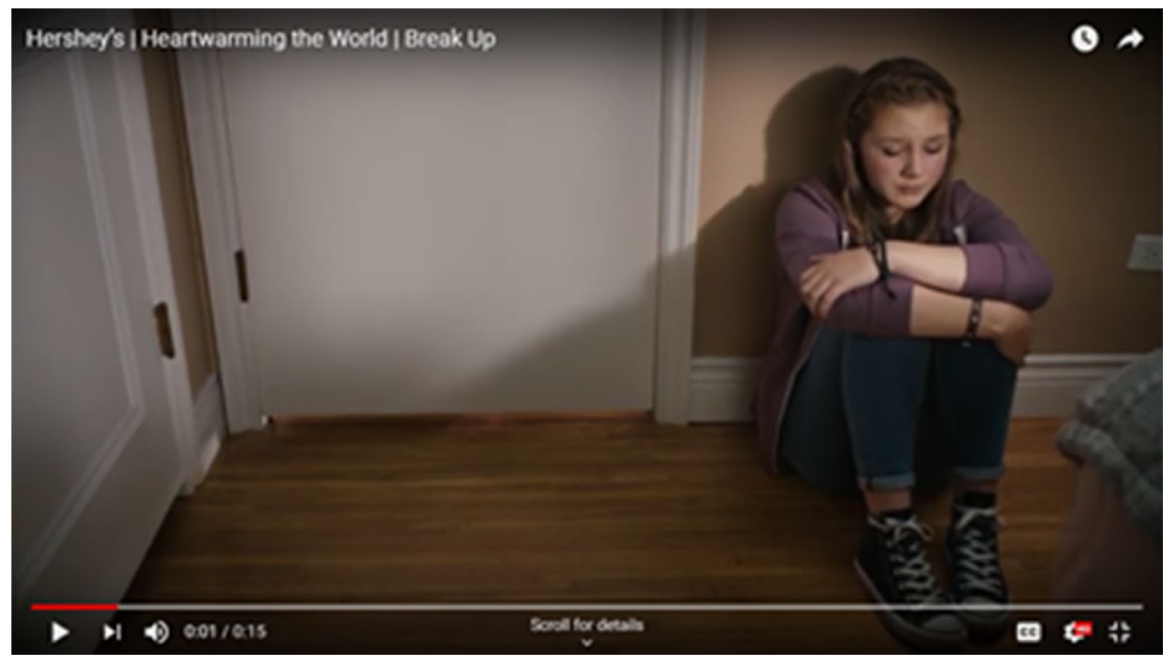

A recent television advertisement in the U.S. pictures a teenaged girl sitting on the floor of her bedroom crying. Her mother comes to the rescue: "I know it's hard Maddie. But I promise, it's going to get better" she reassures her, sliding a Hershey bar under the door, over the background lyrics "Whenever you're losing, I'll celebrate ya, appreciate ya." (https://www.youtube.com/watch?v=Ob-iwWY15MY)

\section{Introduction}

While Hershey eases adolescent pain by courting the sweet tooth, a host of global health organizations recommend dramatic reductions in sugar consumption (Erickson et al. 2017). Using micro-sociological concepts, we explore how middle class, ethnically diverse families in the U.S. engage in a disjointed dance of deprivation and indulgence as they navigate the contradictions of sugar. Bombarded by competing narratives from medical, commercial, parenting, and family sources, parents and children employ an array of tactics, some rhetorical and some more physical, to minimize dissonance. We expose how families sustain a coherent performance despite their contradictory practices. Our findings indicate that health researchers must take into account the emotional and social costs of complying with health advice if their work is to have an eventual impact on families.

Erving Goffman's dramaturgy, combined with additional insights from more contemporary interactionists, inspires a new concept that we call health performance strategies. These are rhetorical and physical tactics for making daily life consistent with one's health ideals. Families in our study dance back and forth between 
condemning and celebrating sugary treats, drawing upon different rhetoric and rationales in different moments. They also develop material practices for physically concealing or safeguarding treats. The health performance strategies described by our respondents illuminate how excessive sugar consumption persists in the United States despite pervasive warnings about sugar. We end by emphasizing the relevance of this research for other countries and the utility of the concept of health performance strategies for other areas of health research.

\section{Research on sugar consumption in families}

Biomedical research on sugar consumption and social science research on family food practices each inform this project. Much of the biomedical research focuses on children with the assumption that eating habits begin early in life and that parents can shape these habits. When sugar composes a large portion of children's diets, it crowds out nutrient rich foods, putting kids at greater risk for metabolic disease, dental carries, obesity, and other conditions (Fidler Mis et al. 2017). Sweet tastes are appealing to most people despite the lack of connection to nutritional value (Powell et al. 2016) with some studies showing that sugar changes human brains in ways that heighten the craving for more sugar (Avena et al. 2008). The challenge for public health officials has been to create rational appeals to convince individuals to sacrifice the alimentary pleasures of excess sugar in order to protect their health.

The U.S. Department of Health and Human Services advises that "Americans should get only $10 \%$ of their calories from sugar. This equals 13.3 teaspoons of sugar per day (based on 2000 cal per day). The current average is 42.5 teaspoons of sugar per day!" (https://www.dhhs.nh.gov/). Despite reductions in soda consumption in the first decade of the century, warnings to limit sugar have not reduced its intake to acceptable levels in the U.S. (Bailey et al. 2018). One reason for this failure may be that such warnings typically mirror the biomedical research by failing to situate individual choices within the interactional contexts of social life. For interactionist sociologists, what counts as "rational" behavior becomes especially complicated in the context of the family, where multiple roles, ideas, and tastes intersect and change over time.

The first U.S. interactionist to attend to these complexities in the study of family food consumption in depth was Marjorie DeVault in her groundbreaking Feeding the Family (1991). DeVault could only speculate on how sugar consumption would soon soar in tandem with the explosive growth in processed foods, the "speed-up" in family life (Wajcman 2008), an upsurge in "eating out," and the rise of the Internet. Families today face an avalanche of sometimes contradictory nutritional advice within a food system that pushes sugar.

European, Canadian, and U.S. research on food provisioning highlights the fear and anxieties of mothers who, more than other caregivers, are held accountable for proper feeding (e.g., Warde 1999; Bugge and Almås 2006; Ristovski-Slijepcevic et al. 2010; Gram and Grønhøj 2015). A discourse of intensive mothering maintains its hegemony, despite feminist gains and Queer Theory efforts to decouple parenting from gender (Zivkovic et al. 2010; Cairns et al. 2013). Mothers are often the ones 
to sort out mixed messages from competing authorities in order to meet the health needs of each individual in their family (Cook 2009a, b; Elliott and Bowen, 2018). They must stay up to date on health recommendations and carefully monitor the personal, biological, social, and emotional needs of their children in order to maximize kids' self-esteem and feelings of belonging (Cook 2009b; Pugh 2009), walking a fine and shifting line between being too relaxed and too rigid (Albon 2005). Although further research is needed on fathers, grandparents, and guardian caregivers as food provisioners (Metcalfe et al. 2009), as well as on families that resist heteronormativity (Allen and Mendez 2018), studies currently show that the moral responsibility for proper feeding is usually pinned on mothers in Western Europe and North America (Beagan et al. 2008; Sutherland 2010).

Children also receive mixed messages about how to eat through mass media, social media, family, peers, and formal education. While most U.S. children today know some basic principles of healthy eating (Schultz and Danford 2016), they are immersed in a food system reliant on heavily processed foods and a children's popular culture that valorizes sweet products as comforting and cool. Advertisers regard kids as a sovereign market (Schor 2004), targeting them with campaigns that elevate the coolness of sweetened products. Fortunately, children are not simply passive dupes of advertising but highly active agents of consumption with competing allegiances (Cook 2008): not only do they want to feel cared for by their families, but they also want to feel they are part of their peer culture (Corsaro 1990; Albon 2005), and consumer culture offers avenues for strengthening social connections with peers (see Zelizer 1985). As children grow older and become more skilled at exerting their agency in determining when, where, and what they eat, parental dietary control tends to deteriorate (Wills et al. 2011; Cairns 2018). It is unfortunate that children's voices are rarely spotlighted in research on family consumption practices (Cook 2008; Pugh 2014; but for exceptions see Curtis et al. 2010 and Cairns 2018). Like mothers, they too are caught in the crosshairs of contradictory messaging about excessive sugar as they attempt to establish their own identity and social relationships.

Sociologists taking an interactionist or a practice theory approach have demonstrated that although families commonly set up household rules to limit sugary food/ drink consumption, these rules are frequently broken by individuals or by-passed by families as a whole (Albon 2005; Halkier 2012; Gram and Grønhøj 2015; Faith 2017) through a variety of innovations such as "cheat days," which may include holidays, birthdays, celebrations, or even every Friday of every week. In practice, families often expand opportunities to break the rules; for example, it is not only Friday, but also Thursday ("little Friday") when rules eventually come to be relaxed (Gram and Grønhøj 2015). Cakes, cookies, ice cream, soda, or fruit drinks are at the center of many special occasions, tying sweetness to excitement. Families also continue to use sugary treats as rewards for good behavior or to comfort sad loved ones (like the teenager consoled by a Hershey bar), thereby deepening sugar's link to caring (Namie 2011; Chen 2016; Faith 2017). Even while they continue to believe that they are limiting their sugar intake effectively, families redefine certain types of sugar consumption as completely acceptable, and these practices become institutionalized (see Warde 2016). Sociologists have yet to make sense of how both rhetorical and 
physical tactics become useful in this dance of alternately upholding and violating household eating guidelines.

\section{A dramaturgical and interactionist lens}

Erving Goffman's “dramaturgy” (1959), Arlie Hochschild's (1989) concept of "family myths," and Allison Pugh's (2009) analysis of the symbolic meanings of consumer goods in children's lives illuminate how sugar retains its stronghold in families. Goffman, in The Presentation of Self in Everyday Life (1959), pictured social life as theater and each individual as an actor on a stage, a metaphor especially useful in studying family life (Collett and Childs 2009). Goffman's concepts including frontstage, backstage, team, impression management, manner, prop, face, facework, slip-up, and performance can be fruitfully applied to the improvised dance around sugar.

The self, for Goffman, is not unitary but multiple, populated by competing allegiances and distinctly different logics of action. Because individuals perform for many audiences and serve on diverse dramaturgical teams, they may encounter moments when a performance pleasing one audience irritates or upsets another audience. Families are a crucible for this type of conflict as many identity projects come together in the family team, complicating the staging of a collaborative construction of family. Because family members juggle competing rationalities tailored for their different audiences and contexts, health warnings will seldom produce only one rational course of family action: for example, parents may find it rational to forbid sweets on a daily basis, but also rational to offer candy when a child is sad.

Although health scholars have applied Goffman's concepts to sites such as hospitals (see Tanner and Timmons 2000), family dietary practices have not become a focus. Eating practices unfold on both a carefully crafted frontstage of theatrical performance, where healthy expectations are condensed into scripts that are well known by family members and supported by props, as well as on a backstage where the daily realities of family food consumption are hidden from public view, known only to intimate friends and family. Importantly for Goffman, compelling performances do not consist of words alone: as the frontstage is carefully set, objects that might hinder the performance are pushed out of sight. Moving sugar consumption to the backstage can be an important performance technique for families wishing to perform as healthy eaters.

In his book Interaction Ritual (1967, p. 5), Goffman defined face as the image of oneself that meshes with socially approved images, and facework as the moves taken to make one's actions consistent with that image (p. 12). Family members risk losing face when they are caught engaging in behaviors that clash with what their frontstage self is supposed to be doing. Impression management requires doing facework to project idealized images of their lives and to present an image of rational order in their family (see Cook 2009b). The ideology of intensive mothering raises the stakes of this performance for mothers in particular who strive for perfection in their food provisioning (e.g., Sutherland 2010). The backstage of family eating 
where dietary recommendations are often compromised, sidestepped, and subverted, is typically hidden from researchers and health-care workers alike.

Differences between household frontstage performance and backstage action were unpacked by Arlie Hochschild (with Anne Machung) in the book The Second Shift (1989). Hochschild detailed the ways couples make sense of the gendered division of labor in their home, finding that some couples who swore that they divided housework "50/50" often actually maintained quite inequitable divisions of household labor. For example, one couple she calls Nancy and Evan Holt insisted that their workloads were equal because Nancy cleaned the upstairs and Evan cleaned the downstairs, without immediately divulging that the lower floor consisted only of the garage, and the upper floor held their entire living quarters (p. 43). An exhausted Nancy Holt invoked the "family myth" of a 50/50 split in order to align her ideals of marriage equality with the messy realities of her marriage. We extend this idea of a family myth to the effort families undertake to make their eating habits align with their health ideals.

Sociologist Allison Pugh built upon the theoretical lenses of both Goffman and Hochschild in Longing and Belonging: Parents, Children and Consumer Culture (2009). Pugh situates children within an "economy of dignity" where certain consumer goods, including toys, clothing, experiences like movies, birthday parties, and potentially even popular foods, may function as "scrip," an anthropological term meaning "tokens of value" which carry symbolic importance and confer dignity within a particular social world (see Pugh 2009, p. 7). As children seek out a feeling of belonging within their family, their peer groups, and the larger society, they draw upon scrip. For example, children might advertise that they had a cool, expensive birthday party in order to gain entrance into peer groups where this scrip serves as a gatekeeper.

The literature on families and food in consumer culture reveals that parents, usually mothers, buy products that foster kids' sense of belonging while also struggling to retain their own maternal dignity and moral self-worth by feeding their children healthy foods (Cook 2009a). Strategies can vary by economic class: Pugh (2009) found that in low-income families, parents look for opportunities to offer their children moments of symbolic indulgence when they can give them products not otherwise in their budget. In higher income families, parents demonstrate care through acts of symbolic deprivation, proving that although they can afford to give their children more, they refuse to spoil their kids. As we shall see, both of these symbolic actions take place in the erratic, middle class family dance around sugar.

\section{Research methods}

From Fall 2013-Spring 2017, a research team consisting of university faculty and undergraduate students conducted open-ended interviews, ranging from 28 to 43 min each, with 67 individuals-40 adults who were raising children and who saw themselves as the primary food provisioner in their home and 27 children (aged 8-15) from these families. In seventeen of these families, we interviewed an adult and only one child, and in the remaining 10 families, we interviewed more than one 
sibling. Parents had to be interviewed and give their consent for their child to be interviewed before any child was interviewed, and children were not interviewed unless they also consented (see "Table 1: Subset of Respondents Cited in this Article" for information on the respondents we have mentioned or quoted in this article).

The first and second authors were university professors who personally conducted about one-fourth of the interviews for this project, but who also incorporated this study into a small "Sociological Research Experience" class that was offered several times. Advanced undergraduates rotated in and out of this course, with each new student becoming an insider in the data collection and analysis, acquiring valuable research skills while contributing their own perspectives to the project. A total of 21 student researchers participated over the four years, with each one conducting at least one interview for the project and participating in weekly analytical discussions. Because of their intensive training in the first month of each semester, almost all completed high-quality interviews. In two instances, student researchers interviewed adults who did not fit the study criteria, and those two interviews were excluded from the dataset. The racial, ethnic, class, gender, age, and sexuality diversity of student team members helped broaden discussions to include sensitivities to difference that the faculty mentors on their own may have missed when interviewing diverse respondents. The strengths and weaknesses of this innovative research/pedagogical design are discussed in depth in Friedman and Graham (2018).

All children have some influence on consumption and so one might wonder why only families with children in the 8-15 age range were selected. The first and second authors of this paper were also both mothers of tween children when they initiated the study. They had both observed that it was not until about age eight that kids are able to obtain foods from outside the family, for example, by biking to the corner store or sneaking sweets from friends or relatives. At this age, kids also are becoming more articulate and observant of their own family and peers, observing when dietary advice is followed and when it is not. The growing awareness of children's agency as consumers (Pugh 2014) suggested to us that eight-year-old interviewees were old enough to offer perspectives on family eating that may not be entirely shared by their caregivers, revealing complexities that may have been missed if only adults and very young children had been interviewed. By age 16, many middle-class U.S. teens can drive a car, allowing them to feed themselves independently from their family at least some of the time, and so we excluded older teens from our study.

All interviewees frequented a recreation center in a middle-class suburb of a large metropolitan area in the southeastern United States where the interviews took place. This recreation center charges an annual fee of about 300 U.S. dollars to local families, making it affordable to the middle classes, too expensive for the poor, and probably unattractive to the wealthiest residents who prefer country club memberships and private gyms. The rec center offered a variety of athletic classes for children, and many of our child participants were involved in these activities. Our particular respondents may have been slightly more health-conscious than average middleclass families, given their presence at a recreation center designed for fitness and sports. We asked to interview parents and children independently from one another, and in all but 3 cases, we were able to do so (sometimes a younger child would 




站。 
remain present during a parent interview, for example). The recreation center provided spaces where private interviews could be discretely conducted.

Our research team found that most people we approached were happy to be interviewed about family food practices, especially since they were usually just waiting for a child or a sibling to finish soccer practice or gymnastics class, for example. For 17 of the 40 parents interviewed, we were also able to interview one or more tween or teen children from the same family, allowing us greater access to different vantage points within the same household. Asking questions about mundane daily practices (e.g., "What did you have for lunch today?") required respondents to push past frontstage ideals and anchor the discussion in their lived experience and everyday practices.

Although our sample reflected the demographic make-up of the recreation center, a public facility catering primarily to food secure, middle-class families with diverse cultural, racial, and ethnic backgrounds, three families in our study could be better described as lower class. Among the 32 women and 8 men interviewed, 26 were White, 4 were Latinx, 4 were African American, 4 were mixed-race, 1 was Indian, and 1 was East Asian. Three were custodial grandparents, and the rest were parents. Among the 27 children interviewed (16 girls and 11 boys), 15 were White, 4 were Latinx, 3 were African American, 3 were Mixed-Race, 1 was Lebanese, and 1 was Indian. All were given pseudonyms.

Knowing that rec center members are generally from the middle classes, we finetuned our understanding of their class by asking respondents about the highest educational level they had attained and their current occupation. Being middle class and living in a large metropolitan area gave our respondents easy access to the Internet's abundance of nutrition information, cultural capital for interpreting health recommendations, a car allowing them to travel to different stores in search of specific foods, and quite often, the time to cook healthy meals. We studied the middle class in part because we wanted to know how even families with the economic means and cultural capital to eat healthy diets often continue to eat too much sugar.

A manageable sample size of 67 allowed us to focus on the richness of respondents' meaning making activities (see Yardley 2000). Following a "grounded theory approach" (Glaser and Strauss 1967; Charmaz 2006), we collected interview data which then served as raw material for generating analytical themes, themes which are thereby "grounded" in the data. In our research team meetings, we collaboratively identified and discussed themes, many of which could only come to light thanks to the diversity of team members.

All interviews were transcribed and uploaded for analysis with the Dedoose qualitative analysis software. We thematically coded the 67 transcribed interviews using keywords related to sugar consumption (such as "treat," "reward," "rules," "restrictions," "soda," "candy," "high fructose corn syrup," etc.). We then paired child and parent/grandparent interviews (in 17 families where that was possible) enabling us to compare narratives emerging from the same family.

The positionalities of the three authors of this paper are reflected in the design of this study and the theme of this article. As White, middle-class professors and mothers of tween children at the time, the first two authors were knowledgeable about health guidelines around feeding children and aware of the status ascribed to popular 
foods and brands at that time. On one hand, they could anchor questions in daily realities they had in common with respondents, cutting through surface performance and into daily practices quickly. On the other hand, it is possible that their identities as mothers may have predisposed them toward a more sensitive understanding of mother respondents than of father, grandparent, or child respondents. The third author, a son of Cuban immigrants raised by his mother, was finishing college and preparing for medical school while working on this project. Like some of the other student researchers, his relative youth and his own ethnically marginalized background added special insights to the collaborative analysis. Most of all, his interest in health inspired this paper's focus on sugar consumption.

\section{Findings}

A clear pattern emerged early in almost every interview. In the opening minutes, each respondent, whether an adult or a child, articulated a very comparable script regarding their healthy eating habits, reflecting their awareness of the dangers of sugar and the need to restrict its intake. Both parents and children usually detailed how their families limit sugar consumption. This strong awareness of healthy eating norms reflects the hegemony of health citizen narratives in the U.S. (see Spoel et al. 2014).

Through a dramaturgical lens, these early moments in each interview embodied family members' frontstage performances of how they eat. Having just met the interviewer moments before, they may have feared being judged, and therefore, chose to play it safe initially by performing an awareness of healthy eating guidelines. As interviewers established greater rapport with respondents, we were able to ask more probing questions such as "Does anyone in your family hide food?" without visibly unnerving the interviewee, a practice also employed by Bugge and Almås (2006). A change in the respondent's manner (posture, expression, mood) signaled by laughter, a smile, a dramatic exhale, or some other gesture, marked a shift away from their healthy eating script and into the backstage of family life. As they recounted their everyday practices, respondents tended to qualify, challenge, or sometimes contradict parts of their initial frontstage performance. Here, we first explore the frontstage performances of healthy eating, and after that, we delve into the backstage where three types of symbolic meanings of sugar emerged as salient features of their daily practices.

\section{Frontstage presentations of family sugar limitation}

Ninety-five percent of the adult main food providers in our sample (38 out of 40) expressed concern about their children's intake of sugary food items such as soda, cookies, and candy. Acknowledging their access to a host of Internet sites and to other health resources such as pamphlets in doctor's offices, parents and grandparents in our study demonstrated their recognition of the importance of decreasing sugar consumption, and they often went further to note that not all forms of sugar 
are equally unhealthy. As Helen, a 41-year-old African American mother of three remarked, "... [my children] would love a lot of cookies and things like that but we don't do high fructose corn syrup and there's a lot of products that have high fructose corn syrup...." Darren, a white father of two in his mid-40s, explained "The processed sugar thing I pay attention to because I'm type II [diabetic]. I pay attention to food labels." Both high fructose corn syrup and processed sugar received scorn from many parents.

Mothers, in particular, expressed how difficult it can be to get kids to eat less sugary foods. Rachel (50), a White mother of two daughters, vented: "It's just a challenge because I buy things that don't have any sugar, and they don't eat them. ...I'd say my guidelines were having as many fruits and vegetables in them as possible and as little sugar." Sometimes Rachel finds herself forced to choose between her children eating yogurt with lots of added sugar or not eating yogurt at all, and she just tries to do the best she can without sparking an argument. Stacy, a White mother of three kids who were swimming at the recreation center pool during our interview, showed off her snack cooler, pointing out that the brand of children's yogurt she brought has "no artificial flavors and that sort of thing, no high fructose corn syrup." She had also packed a flavored drink with "only eight grams of sugar." Stacy's cooler served as a theatrical prop reinforcing her performance of sugar vigilance and anchoring her words in actual practices.

It is not only mothers who engage in the struggle to limit sugar. Deacon, a White grandfather of two and prediabetic, has read a great deal about the dangers of sugar. $\mathrm{He}$ is alarmed at how much sugar his granddaughter Astrid (mixed race, 11) eats, referring to her as a "sugar junkie": "I mean I've seen people on heroin that have an easier time than she does when you try to pull her off the sugar." Deacon takes it "one step at a time," altering family eating practices incrementally to see how the kids tolerate it.

Along with parents and grandparents, most children are aware of the dangers of excessive sugar, and while they appreciate the love their families express by limiting junk food consumption, they are sometimes resentful of household restrictions. Alexandra who is White and 12 years old remarked: "My parents cut down the candy and ice cream, chips and soda and sugar... to keep me healthy." Children recalled bringing healthier eating habits into their own home, as when Astrid's brother Ivan (mixed race, 13) learned about the dangers of sugary soda pop in school and told his family that they should cut back on soda. A White eleven-year-old we are calling Andrew remarked that he often looks at food labels in stores, and so we probed further about what exactly he pays attention to: "Sugar, carbohydrate... potassium, stuff like that. I like to look at the vitamins and how much iron there is, and I like to look for the protein too. So, protein and sugar is my main thing."

Andrew's mother, Susan, is a 40-year-old White mother of three who teaches her children to "go to the refrigerator first instead of the pantry because the refrigerator has the freshest stuff" and "try not to eat too much sugar, like any, like no sugar after 5 o'clock ever (because they just spazz out)." Susan has learned through Internet research that her children "can live to be a hundred if [they] eat properly now." Among our many respondents, she represents the supermom-a mother who is trying to do everything perfectly for her kids. 
Camille, a divorced 32-year-old Puerto Rican mother of two tells her children, "'You have to ask! You don't open the fridge, you don't open the cupboards unless you are asking for permission!' That kind of makes me feel like I have a little bit of control over what they are eating...." Employed as a school cafeteria "lunch lady," Camille saves money by purchasing snacks in bulk from a warehouse store. She resorted to putting a padlock on her pantry after her children ate $\$ 400$ worth of donuts and other snacks in the first week of summer vacation, snacks that were purchased to last all summer. Not only is she exasperated by their unhealthy eating habits, she also cannot afford to satisfy their insatiable drive for sugar, and so she physically separates her kids from the stockpile of treats.

Parents often pointed to other people's children as examples of how not to eat. Marcela (51), who is originally from Argentina, noted that her own 11 children eat "much better" than her kids' friends do:

Interviewer: Why do you think that is? What sort of foods do their friends eat? Marcela: Hmm...I don't know. It's not...maybe the cereal is more sugary. They have access to soda, chips, eh...hotdogs, you know? At some point we discontinued those. Because they don't make a meal, and you know, there are healthier choices.

Susan complained: "It's just amazing the crap these people feed their kids, and thinking about it, I see people with kids around my kids age walking around with cans of like a Sunkist orange soda. Who doesn't love one of those, but there's $45 \mathrm{~g}$ of sugar in a can!" In pointing to what other people's kids eat, and disparaging brand names with unhealthy ingredients, mothers can feel proud of their own mothering skills (Chen 2016; Cairns 2018) while also reaffirming their middle-class sensibilities (see Shugart 2014).

Withholding sugary drinks and treats and choosing healthier alternatives demonstrates what Allison Pugh (2009) calls symbolic deprivation. In blocking children's access to excessive sugar, parents show that they refuse to spoil their children and risk their children's health. However, family life with less sugar is not simple to achieve, in part, because biological cravings are powerfully bolstered by commercial appeals and also by children's peer cultures. As tweens and teens grow more confident and independent, they exert more and more influence over their own eating, making the idealized frontstage portrayal of healthy eating increasingly difficult to sustain (Cook and Kaiser 2004).

\section{The backstage of family eating, where sugar means love, sanity, and secret pleasure}

A fascinating collective dance pivoting between restriction and frequent enjoyment of sugary foods and drinks animates the backstage of these families, erupting through three kinds of symbolic meaning. First, like the mother of the teen in the Hershey's advertisement, our respondents actively pair sugar with love. Second, busy parents sometimes just give up and relax their sugar limitations in order to save their sanity. Third, parents and children alike find private ways to enjoy sugary 
treats, sometimes hiding and hoarding treats, actions that underscore the treasured status these items hold. Outsiders (like members of our research team) who peek into the backstage might be alarmed at the contradictions between idealized performance and daily realities, but family members themselves seemed to regard the frequent enjoyment of sugary products as consistent with their performance of health.

\section{Sugar $=$ love}

Like the parents studied by Cook (2009b), these parents recognize that kids are immersed in a consumer culture continually luring them toward sugar, salt and fat, and that in order to feel that they belong, kids need treats sometimes. Sugary treats are a stand-in for love, but there are several ways that association manifests. First, love means honoring and celebrating special occasions with unusual indulgences. Interviewees distinguished the foods allowed on holidays and birthdays from "everyday" foods. Mothers, in particular, frequently assured us that they allow their children to have sugar sometimes, because, as several put it, "I am not a food Nazi," implying that only a fascist would eliminate all sugar from the home. Some explained that any child raised without occasionally eating candy or drinking sugary beverages would feel deprived and left out of American culture. Likewise, any mother who would deny her children the corresponding sense of belonging would fail to be a good mother, a sentiment that supports the findings of Cook (2009a) and Albon (2005), among others.

When Halloween arrives on October 31st each year, U.S. children typically dress in a costume and go door-to-door requesting candy, shouting "trick or treat!" Even the nutrition-focused supermom we are calling Susan gives in:

Halloween is coming up and I'm going to find candy wrappers for the next three months, and it just is what it is. You know, I'm not going to be a Nazi, I'm not. It's Halloween, they have candy, they get it from school, they get it from here, they get it from there. You know, it's kind of inevitable. It's not the end of the world.

To deny her children the pleasures of Halloween candy would be to mark them as outsiders in children's peer cultures. She shows love by helping her children feel they belong in their social worlds, and this symbolic indulgence in Halloween candy is one facet of her performance as a good mother.

Other parents talked about relaxing rules for Christmas, birthdays, and other special occasions. Elisa, a 40-year-old Asian-American mother of two, clarified that on special occasions, all bets are off: “... when it's their birthday they can eat the entire cake if they want, if it's a wedding and there's cake and candy around, at school, we don't, so yeah.” Susan echoed Elisa's sentiment, “... I call them like cheat days that they can have, you know, all their candy, all the sugar. I like to make desserts and pies. We go all out on the holidays, but those are cheat days." Gabriella, who describes herself as a single Brazilian, Puerto Rican and Black mother of two remarked that Friday, Saturday, and Sunday are the three "snack days" she allows each week, and that whenever the family eats junk food 
on a different day, they have to forfeit one of their three weekend snack days. She explained "... why allow these days at all? Well, because I have my cheat days too. And they are kids and want to have fun every now and then." On special occasions and cheat/snack days, sugar bolsters familial bonding and joviality, while also satisfying the sweet tooth of parents and children alike. Relaxing the rules lets mothers enjoy a break from their regular vigilance without compromising their identities as good mothers.

Rewarding children for good behavior has long been a staple of good parenting. Many children said that their parents reward them with sweet treats. Thirteen-yearold Sandy recounted: "After my basketball game yesterday-I made half the shotsshe wanted to congratulate me, so she got me a little bag of gummy worms. I ate those and was very happy." Candy is both positive reinforcement and a compliment in a colorful wrapper.

Loving parents are responsible for cultivating the development of skills in their children and in helping children learn to be generous. Baking is a great opportunity for kids to develop a skill which yields shareable treats. Deacon, the grandfather of Astrid, complains about her sugar addiction, but he is proud that she is learning how to bake cookies at age 11 and that she shares this activity and the cookies with a friend. A bad sugar habit like Astrid's is tolerable, it seems, if it is satisfied through an enrichment activity, and especially if this creates the opportunity to share.

Food can also be a symbol of family bonds and heritage. Andrew (11), the ingredient-reading son of supermom Susan, told us that their family almost never buys cookies except for Danish cookies. When asked why, he responded that he and his twin brother had to bring something to school representing their Danish heritage one day, and they chose Danish cookies. Since that time, the twins occasionally ask to buy them again to "celebrate their heritage." Similarly, traditional desserts are ritually enjoyed on holidays, and restrictions are relaxed in honor of the tradition-these foods highlight the specialness of the occasion and help strengthen family bonds.

Parents have not only nutrition but also their children's sense of "belonging" in mind especially while anticipating the school lunch period. Gabriella has an income low enough that her two children qualify for free school lunch, but she refuses to send extra money for them to buy ice cream for dessert, explaining "They tried a couple of times [to get ice cream money], but I think it's just the peer pressureEveryone is getting one so I want one, that type of thing." So that they get "something," she packs a dessert-type snack for them each day as a substitute for the ice cream that other kids are eating.

Many children regularly brought to school a lunch that was packed by a parent. The packed lunch bag/box represents a mobile symbol of love. Because it travels from home to school, parents consider the expectations of both social contexts when packing lunches. Several described how they try to include a "fun food" or treat so that their child will not feel deprived and to give the child a break from daily school rigors (also found by Harman and Cappellini 2014).

Caleb, a divorced White father who has his two kids every other week, remarked "I always make sure they have a piece of fruit, some sort of protein, a drink of some sort, most times water, but it might be something like Gatorade ${ }^{\circledR}$ [a sugary sports drink]. And (with a chuckle) I give them a treat of some sort where I relax the rules 
on healthiness." Twelve-year-old Blakeley, who is White, itemized the contents of her lunchbox adding that there is always "a sweet thing...the snack and sweet thing vary...I have things like a bag of granola or graham cracker with chocolate on top from the store. And sometimes, I get Oreos."

Treats from the lunch bag are coveted and therefore tradeable. They serve as "scrip" in the lunchroom, signaling a child's status within children's consumer culture and conferring dignity (Pugh 2009). Baylor, a White nine year old, told us that trading items from his lunch box with other kids is normal for him, "Oh yes, I do it all the time." We asked which items the other kids want, and he responded "My granola bars, my juice. And I get some great stuff out of it too!" A cool treat like Oreo cookies or granola bars in the lunch box materializes parental love by demonstrating an understanding of a kid's quest to feel like part of their school peer group.

\section{Sugar = sanity}

With the "speed-up" in family life, families want their time together to be harmonious and productive, not caught up in recurring arguments. This means that dietary ideals often give way to short-term comfort as parents settle for less healthy and more sugary foods in busy moments. Our parent respondents detailed a grueling ritual of coming home from work and then carting around children to extra-curricular activities, helping with homework, shopping, keeping house, and cooking. Navigating each individual family member's tastes, allergies, health conditions, and schedule is exhausting to them. The work of feeding the family is in flux as children grow to assert their agency, new tastes and health conditions emerge, new guidelines are released, and new products appear on store shelves.

Parents compared it to continually trying to hit a moving target and admitted that they sometimes lacked the strength to enforce their own eating restrictions. Rachel, a White mother of two girls adopted from Central America: "Well, it used to be easy when they were toddlers. I mean, everything they ate was healthy because I was the only one feeding them. And they didn't have an opinion...It just definitely gets harder as they get older." Today, Rachel buys candy to take along on car trips, because, as she put it, "we just want peace in the car."

As a child becomes more skilled at getting what they want, the busy-ness of family life combined with tweens' growing personal agency can amplify discord and stress. Parents complained about how tired they were of all the nagging. Camille parodied her kids:

"I'm hungry, can I have a snack, Can I have a snack? I'm hungry." It's constantly. We're in the car. "Can I have a snack?" "I'm hungry." They see McDonalds, "Can I have a snack?" "Can I have something?"

Her son, Tomas (Puerto Rican and Dominican, 8) is annoyed when his brother asks for candy at the grocery store check-out lane, and in those moments, he covers his ears as a request to his mother not to yell. He himself is learning to be strategic- - he tries to catch his mother in a weak moment (he sees this weakness "in her eyes") before asking her politely for treats. 
When they are emotionally drained, parents more often allow sugary foods and drinks as pacifiers to ease conflict and get through the day. For example, most parents noted that they try not to bring their kids with them to the grocery store due to the nagging, but when they do, they sometimes make concessions just to eliminate conflict. Marcela (51), a mother of eleven, made it clear from the start that her children are almost never allowed to consume sugar, but later in the interview, she revealed part of the family's backstage: "That's why they want to go to Sam's Club with me because you know, we grab a soda. They have the snack bar.... Yeah. But that's that." Her children have figured out that going along to a big box store with a snack bar will allow them to get otherwise forbidden treats.

As tweens and teens become involved in structured activities, the pressure mounts on parents to feed them quickly, and this can result in allowing more sugar, salt, and fat into their bodies through fast food and processed convenience foods. Siblings typically have different afterschool schedules, and grabbing a quick bite at a fast-food restaurant can sometimes feel like the only expedient option. Kara, who is a White, 37-year-old mother of four and a dietician in training, tries to get dinner ready very early so that everyone can eat; but on the busiest days, she gives in and takes the kids to "McFats" (her name for McDonalds) so that they can at least have some kind of dinner. Kori (white, 10) detailed how dinner must fit around both her dance schedule and her sister's gymnastics class. Her father, Darren, who is responsible for grocery shopping and cooking, noted that the only time the family can eat together is at 5:00 pm, and even then, one daughter will be late for gymnastics class. Sometimes they get fast food on the run, which Darren rationalizes as a "treat" for his girls. While it is an expedient way to prevent conflict and get everything accomplished, fast food also usually comes with added sugar, as parents and kids well know.

\section{Sugar $=$ secret pleasures}

Many parents, especially mothers, admitted that they too covet sugary snacks, especially when they feel stressed. Kara described her own secret chocolate habit by admitting that she and her husband "hide a lot of stuff (laughing)... A lot of my stuff I put away and I like dark chocolate or just chocolate in general... Geesh, I wonder why [my kids hide candy] when I am like hiding it myself (laughing)." By hiding and enjoying the very treats that they keep away from their children, parents mask their personal weaknesses while saving face as provisioners of healthy food. They also model this behavior for their kids. Kara knows that her children see through her facade-her candy stash has become an open secret in their home, and it is frequently raided by her children. Through her actions, she underscores that candy is something worth hiding and hoarding for oneself.

Kara's oldest daughter Sandy (white, 10) has a finely tuned method for hiding candy: Looking through the pantry, "I'll see a bag of candy or something. Sometimes, after I see my mom open it, it's not as visible to see that I have stolen it... Sometimes I'll take five pieces, hide it in my room and stash away candy." Other times, candy comes directly from another family member's secret stash, a store, or 
another home. Allen (white, 8), Sandy's brother, gets junk food at their grandparents' house and carefully sneaks it into his home by waiting until his mom is distracted on the phone or in the shower - the clandestine nature of sneaking candy is part of the thrill. The universal pleasure of having a secret, even if it is a secret that other family members have strong suspicions about, adds to the enjoyment (see Vangelisti 1994).

We saw a similar pattern in several other families. Alexandra (white, 12) hides treats in the pantry and gets annoyed when her dad raids her stash. Mary Jane, a White mother of four in her 30s, says she always finds kitchen chairs in front of the refrigerator, a sign that her kids have been trying to climb up to find the treats that she reserves for packing school lunches. Astrid makes chocolate chip cookies and puts them up high in a futile effort to keep them from her brother. Kori sneaks to the refrigerator to spray Readywhip ${ }^{\circledR}$ whipped cream into her mouth when no one is looking. Her mom is aware that this takes place, and although it violates the household rules, she does not punish Kori for it, but merely calls her a "stinker." In fact, there is very seldom any kind of punishment for sneaking treats, and the playfulness around hiding, hoarding, and raiding private stashes underscores the normalcy of these behaviors. Even when these secret stashes are discovered, the culprit is not held accountable, which indicates that breaking eating rules has come to be expected. These examples underscore how a family's performance as a team of healthy eaters is sustained in part by physically moving some sugar consumption out of plain view.

\section{Discussion}

Given the prevalence of backstage sugar indulgence and its normalization among our respondents, it seems clear that these families with the resources to eat very healthy diets still consume more sugar than the guidelines recommend. We have seen that on the frontstage, families spotlight the practices of sugar deprivation/limitation they uphold, but behind the theatrical curtain, a disjointed dance of deprivation and indulgence is incessant, in the interest of showing love, maintaining sanity, and enjoying private moments of deliciousness. Families smooth out the contradictions through narrative and through other more physical tactics (like hiding treats) in order to save face and sustain a coherent performance.

When respondents told us they were healthy eaters, but then revealed that all bets are off on cheat days, we were reminded Arlie Hochschild's (1989) analysis of couples who developed family myths to reconcile their egalitarian marriage ideals with their lived realities. In the same way, our respondents engage in what we call "health performance strategies" to reconcile their frontstage narratives of healthy eating with daily practices. Fortunately for those who study social science and health behavior, this term is broad enough to extend beyond diet to other behaviors such as exercise, relaxation, hand washing, and avoidance of drugs and alcohol. For any health-related behavior, we can picture families employing health performance strategies in order to make their backstage practices coherent with their frontstage performance. 
Our study's inclusion of parents and children from the same family improved our analysis in ways that we did not fully anticipate beforehand. Early in the project, just as we were beginning our interviews, we contemplated whether parents would stick to a healthy eating performance throughout their interview while children would immediately divulge backstage realities. What we found instead was that both parents and children began their interviews by presenting their family as healthy eaters. When asked questions that anchored the discussion in specific practices, like what they ate for breakfast or packed for lunch that day, both parents and children exposed the family's frequently excused and normally concealed sugar habits. By insisting that these exceptions were allowable, they could save face and protect their family's collective performance. Parents preserved their own dignity as food provisioners, and children safeguarded the dignity of the family's food provisioner, usually a mother whom they love despite her imperfections (see Cairns 2018, p. 181). Almost always, parents and children from a family independently corroborated one another's narratives.

There were very few of what Goffman called "slip-ups," in this case meaning moments when performers' accounts of their actions ruined their family's frontstage performance. Instead, we observed a pattern of similar, well-rationalized exceptions to healthy eating norms. These frequent exceptions might appear, to some observers, as incriminating proof that our interviewees were untruthful or insincere interviewees. However, Goffman would have us view our respondents as mostly sincere: sugar limitation is an ideal that they strive for in daily life and, in their finest moments, accomplish. Their health performance strategies insulate this image of themselves from scrutiny by themselves and others.

Parents did not treat their many rationalizations for sugar indulgence as anything out of the ordinary-instead they normalized them in a variety of way: "I'm not going to be a food Nazi!" "Kids need a treat sometimes!" "I have my cheat days too!" Tweens and teens also articulated agreed-upon rationales, as when Sandy recounted getting gummy worms for basketball success and when Andrew justified eating Danish cookies by appealing to his family heritage. Holidays, restaurants, grandparents' homes, busy days, concerts, movies, birthday parties, ball games, visits to stores with snack bars, and other opportunities to relax the rules seemed completely normal to our respondents. In the dance of daily life, symbolic deprivation shifts to symbolic indulgence and back again in the blink of an eye, enabling middle-class families to manage their lives. This novel finding extends Pugh's analysis in useful ways, showing that contrasting forms of symbolic work can peacefully coexist. The unapologetic normalization of sugar indulgence through such health performance strategies may hold the key for understanding why excessive sugar intake continues to be a problem.

\section{Conclusion}

The health performance strategies we identified in the realm of food practices move beyond earlier research about cheat days and holidays to involve an array of other rationales at work in families including family heritage, belonging, 
children's busy schedules, and accomplishments, all justifiable reasons for allowing sweet treats. Like Goffman, we demonstrate that team performances depend not only upon narrative but also upon patrolling family members and managing the setting through a careful physical placement of objects (such as treats) away from view. While parents put treats up high, avoid bringing their children to stores with them, padlock the pantry, hide a stash of chocolate, and follow the candy wrapper trail to their child's bedroom, their children stow candy in secret hiding places, sneak to the corner store for sweets, and accompany parents to stores with snack bars. These backstage physical tactics open new, clandestine opportunities either to eat treats or to regulate them. Both types of strategies, rhetorical/discursive and physical/material, function to preserve the image of a healthy family while enabling deviance behind the scenes.

Tweens and teens emerge as full-fledged consumers with agency and impact in our study. They learn the rationales for sugar consumption that carry weight with their parents (baking as an enrichment activity, sharing the baked goods, celebrating Halloween or a birthday), and they strategize about when to ask for a treat (Tomas examining his mother's face for "the look") or how to sneak food into the house (Allen waiting until his mom is distracted). Hiding behaviors can be learned by observing parents do the same thing, as Kara suspects her children have done. A key finding of this study is that parents and children have a lot in common: most of them enjoy sugary treats, and many find ways of getting them without upsetting the family's collective performance of healthy eating.

A broader implication of this study is that public health warnings discouraging sugar consumption are not a panacea. In a food system flooded with sugary products, temptations are difficult to resist. In middle-class U.S. families, as we have seen, the problem is not so much a lack of knowledge about the dangers of excess sugar, but rather, the inherent difficulties of putting this knowledge into practice within the emotional context of the family and within the broader context of a sugarloving consumer society.

Given the ways that biological and social forces combine to enable families to forbid their cake and eat it too, public health institutions should do more than issue warnings. Revolutionizing diets may require reducing the parameters on consumer choice, and recent history demonstrates how this is possible. In the United States between 1999 and 2008, soda pop, which had seen a meteoric rise in popularity from 1960 to 1999, and which still accounts for about one-third of all sugar consumption in the U.S., met with effective resistance. Thirty-four U.S. states welcomed regulations restricting soda sales in schools, while alternatives to soda became widely available not only in schools, but also in stores, workplaces, "soda" machines, and restaurants. Marion Nestle reports in Soda Politics: Taking on Big Soda (and Winning) (2015, p. 33), "All age groups report drinking less soda than they did in the late 1990s, a trend that reflects replacement of carbonated, sugar-sweetened sodas with sports drinks, teas, diet drinks and bottled waters." In this example, structural changes regulating availability of soda contributed substantially to a reduction in sugary soda consumption.

Unfortunately, the soda success story has not reduced sugar intake to acceptable levels. Researchers have proposed improving availability of low-cost, healthy food 
and drink options and assisting communities in organizing for change (Khan et al. 2009). Because highly processed, sugar-laden products are often more lucrative for producers than less processed alternatives, corporate resistance can be formidable. Governments may have to shift toward more draconian measures, such as the recent ban on underage purchase of junk food in several states in Mexico in order to prevent obesity and thereby reduce the impact of COVID 19 (Reiley 2020). Structural changes to make sugary products less available, while making healthier alternatives easily available, seem essential given our findings.

Finally, high sugar intake is not the only health crisis in which professional advice is not well heeded. At the top of our minds as we finished this article was COVID 19 and the quite common refusal in the U.S. to socially distance and wear masks; people find ways around such guidelines just as they do around sugar warnings. In either case, providing individuals with the best information and trusting them to make the right decisions, as neoliberal ideology demands, is not always enough. A cultural shift that prioritizes health requires first understanding how unhealthy behavior is embedded in the backstage daily lives of individuals and families and then changing the structural and cultural context that makes undesirable behaviors so tempting.

\section{Limitations and suggestions for future research}

As a qualitative project, this study is unable to pinpoint causal factors in the way that some experimental or statistical research methods strive to do. The trade-off is that we access the interpretive understandings of food behaviors that quantitative studies typically miss.

Social scientists and public health researchers studying family food practices in the U.S. have most often, and justifiably, focused on survey responses (part of the frontstage) of lower income families suffering from food insecurity rather than families in the middle class. We believe that the middle class should not be overlooked in studies of food consumption because about half of adults in the U.S. fall into the middle class, according to the Pew Research Center (Kochhar 2018). This is a segment of society with sufficient time and energy to study healthy eating guidelines. Our middle-class participants were involved in a fitness-oriented recreation center and, therefore, may have a particularly strong understanding of sugar's dangers. The fact that they were likely more health-conscious than typical middle-class families may harm the generalizability of the research. It also underscores the significance of our findings: not even these families can avoid sugar indulgence on a regular basis.

It might seem that simply observing families prepare and eat food would reveal more about the give-and-take of daily interaction than interviews could uncover. Not only is the opportunity to observe more difficult to achieve, observation of private family spaces can sometimes become somewhat disruptive and intrusive, slowing down these busy families and discouraging respondents from being as forthcoming in their narratives. Instead, we interviewed multiple members of a family whenever possible and aimed to establish great rapport that would allow access to the backstage of these families. Of course, there are layers and layers of backstages, each 
bounded by a smaller and smaller circle of intimacy, the smallest of which would be hard for researchers to access regardless of research method.

The study was limited by its focus on the urban United States, limiting generalizability to other countries and to rural areas within the U.S. where childhood obesity rates are even higher and eating practices may differ (Johnson and Johnson 2015). Our review of existing literature shows that Canadian and Western European families participate in at least some of the health performance strategies outlined here. But there has been little research on poorer nations at great risk of experiencing an obesity epidemic as the corporate food system continues to globalize (Zobel et al. 2016). High rates of childhood obesity and diabetes type 2 in the U.S. (Grossman et al. 2017) make this study relevant to scholars and health officials striving to prevent a similar public health tragedy in other countries.

Future research should examine the backstage realities of less privileged families as well as ethnically and racially segregated communities within the U.S. and in other countries in order to learn how more diverse families regard and act on the prevailing medical and health-care advice about sugar. Longitudinal research would be useful in analyzing how families adapt as their children age. Finally, with so much attention on mothers as food providers, there is a need for new research on a growing number of families that resist heteronormativity or traditional gender norms.

Acknowledgements The authors would especially like to thank Dr. Ginna Husting, the anonymous reviewers for this journal, and all of the phenomenal student researchers who participated in this project.

\section{References}

Albon, D.J. 2005. Approaches to the study of children, food and sweet eating: A review of the literature. Early Child Development and Care 175 (5): 407-417. https://doi.org/10.1080/030044304200024 4055 .

Allen, S.H., and S.N. Mendez. 2018. Hegemonic heteronormativity: Toward a new era of queer family theory. Journal of Family Theory \& Review 10 (1): 70-86. https://doi.org/10.1111/jftr.12241.

Avena, N.M., P. Rada, and B.G. Hoebel. 2008. Evidence for sugar addiction: Behavioral and neurochemical effects of intermittent, excessive sugar intake. Neuroscience and Biobehavioral Reviews. https:// doi.org/10.1016/j.neubiorev.2007.04.019.

Bailey, R.L., et al. 2018. Sources of added sugars in young children, adolescents, and adults with low and high intakes of added sugars. Nutrients. https://doi.org/10.3390/nu10010102.

Beagan, B., et al. 2008. 'It's Just Easier for Me to Do It': Rationalizing the family division of foodwork. Sociology 42 (4): 653-671. https://doi.org/10.1177/0038038508091621.

Bugge, A.B., and R. Almås. 2006. Domestic dinner: Representations and practices of a proper meal among young suburban mothers. Journal of Consumer Culture 6 (2): 203-228. https://doi. org/10.1177/1469540506064744.

Cairns, K. 2018. Relational foodwork: Young people and food insecurity. Children \& Society 32 (3): 174-184. https://doi.org/10.1111/chso.12259.

Cairns, K., J. Johnston, and N. MacKendrick. 2013. Feeding the "organic child": Mothering through ethical consumption. Journal of Consumer Culture 13 (2): 97-118. https://doi.org/10.1177/14695 40513480162.

Charmaz, K. 2006. Constructing grounded theory: A practical guide through qualitative analysis. Thousand Oaks: SAGE. https://doi.org/10.1016/j.lisr.2007.11.003.

Chen, W.T. 2016. From "junk food" to "treats.” Food, Culture and Society 19 (1): 151-170. https://doi. org/10.1080/15528014.2016.1145008. 
Collett, J.L., and E. Childs. 2009. Meaningful performances: Considering the contributions of the dramaturgical approach to studying family. Sociology Compass 3 (4): 689-706. https://doi.org/10.111 1/j.1751-9020.2009.00223.x.

Cook, D.T. 2008. The missing child in consumption theory. Journal of Consumer Culture. https://doi. org/10.1177/1469540508090087.

Cook, D.T. 2009a. Children's subjectivities and commercial meaning: The delicate battle mothers wage when feeding their children. In Children, food and identity in everyday life, ed. A. James, A. Kjørholt, and V. Tingstad, 112-129. London: Palgrave Macmillan. https://doi.org/10.1057/97802 30244979_7.

Cook, D.T. 2009b. Semantic provisioning of children's food: Commerce, care and maternal practice. Childhood 16 (3): 317-334. https://doi.org/10.1177/0907568209335313.

Cook, D.T., and S.B. Kaiser. 2004. Betwixt and be Tween. Journal of Consumer Culture. https://doi. org/10.1177/1469540504043682.

Corsaro, W. 1990. Children's peer cultures. Annual Review of Sociology. https://doi.org/10.1146/annur ev.soc.16.1.197.

Curtis, P., A. James, and K. Ellis. 2010. Children's snacking, children's food: Food moralities and family life. Children's Geographies 8 (3): 291-302. https://doi.org/10.1080/14733285.2010.494870.

DeVault, M.L. 1991. Feeding the family: The social organization of caring as gendered work. Chicago: University of Chicago Press.

Elliott, S., and S. Bowen. 2018. Defending motherhood: Morality, responsibility, and double binds in feeding children. Journal of Marriage and Family 80 (2): 499-520. https://doi.org/10.1111/ jomf. 12465 .

Erickson, J., et al. 2017. The scientific basis of guideline recommendations on sugar intake: A systematic review. Annals of Internal Medicine 166 (4): 257-267. https://doi.org/10.7326/M16-2020.

Faith, M.S. 2017. Parental food rules and children's eating: Intended and unintended consequences. In Eating disorders and obesity: A Comprehensive handbook, 3rd ed., ed. K. Brownell and T. Walsh, 97-102. New York: Guilford Publications.

Fidler Mis, N., et al. 2017. Sugar in infants, children and adolescents: A position paper of the European Society for Paediatric Gastroenterology, Hepatology and Nutrition Committee on Nutrition. Journal of Pediatric Gastroenterology and Nutrition 65 (6): 681-696. https://doi.org/10.1097/MPG.00000 00000001733.

Friedman, J., and L. Graham. 2018. A kitchen table pedagogy for interrogating whiteness through a research experience course. Sociology of Race and Ethnicity 4 (1): 142-153.

Glaser, B.G., and A.L. Strauss. 1967. The discovery of grounded theory: Strategies for qualitative research, observations. Chicago: Aldine. https://doi.org/10.2307/2575405.

Goffman, E. 1959. The presentation of self in everyday life. New York: Doubleday.

Gram, M., and A. Grønhøj. 2015. There is usually just one friday a week. Food, Culture and Society 18 (4): 547-567. https://doi.org/10.1080/15528014.2015.1088189.

Grossman, D. C. et al. (2017) 'Screening for obesity in children and adolescents us preventive services task force recommendation statement', JAMA-Journal of the American Medical Association, 317(23), pp. 2417-2426. https://doi.org/10.1001/jama.2017.6803.

Halkier, B. 2012. Consumption challenged: Food in medialised everyday lives. Burlington, VT: Ashgate. https://doi.org/10.1177/0094306112438190aa.

Harman, V., and B. Cappellini. 2014. Unpacking fun food and children's leisure: Mothers' perspectives on preparing lunchboxes. Young Consumers. https://doi.org/10.1108/YC-11-2013-00410.

Hochschild, A. 1989. The second shift: Working parents and the revolution at home. New York: Viking.

Johnson, J.A., and A.M. Johnson. 2015. Urban-rural differences in childhood and adolescent obesity in the United States: A systematic review and meta-analysis. Childhood Obesity. https://doi. org/10.1089/chi.2014.0085.

Khan, L.K., et al. 2009. Recommended community strategies and measurements to prevent obesity in the united states. Morbidity and Mortality Weekly Report 58 (RR-7): 1-26.

Kochhar, R. 2018. The American middle class is stable in size, but losing ground financially to upperincome families, Pew Research Center. https://www.pewresearch.org/fact-tank/2018/09/06/theamerican-middle-class-is-stable-in-size-but-losing-ground-financially-to-upper-income-families/. Accessed 2 Sept 2020.

Metcalfe, A., C. Dryden, M. Johnson, J. Owen, and G. Shipton. 2009. Fathers, food and family lifeChanging families, changing food. In Fathers, food and family life. In changing families, changing 
food, ed. P. Jackson, 93-117. London: Palgrave Macmillan. https://doi.org/10.1057/9780230244 $795 \_6$.

Namie, J. 2011. Public displays of affection: Mothers, children, and requests for junk food. Food, Culture and Society 14 (3): 393-411. https://doi.org/10.2752/175174411X12961586033645.

Powell, E.S., L.P. Smith-Taillie, and B.M. Popkin. 2016. Added sugars intake across the distribution of US children and adult consumers: 1977-2012. Journal of the Academy of Nutrition and Dietetics 116 (10): 1543-1550.e1. https://doi.org/10.1016/j.jand.2016.06.003.

Pugh, A. 2009. Longing and Belonging: Parents, children, and consumer culture, 1st ed. Berkeley: University of California Press.

Pugh, A.J. 2014. The theoretical costs of ignoring childhood: Rethinking independence, insecurity, and inequality. Theory and Society. https://doi.org/10.1007/s11186-013-9209-9.

Reiley, L. 2020. Mexico moves to Ban junk food sales to kids. Tampa Bay Times, 23 August.

Ristovski-Slijepcevic, S., G.E. Chapman, and B.L. Beagan. 2010. Being a "good mother': Dietary governmentality in the family food practices of three ethnocultural groups in Canada. Health 14 (5): 467-483. https://doi.org/10.1177/1363459309357267.

Schor, J. 2004. Born to buy. New York: Scribner.

Schultz, C.M., and C.M. Danford. 2016. Children's knowledge of eating: An integrative review of the literature. Appetite 107: 534-548. https://doi.org/10.1016/j.appet.2016.08.120.

Shugart, H.A. 2014. Food fixations: Reconfiguring class in contemporary us food discourse. Food, Culture and Society 17 (2): 261-281. https://doi.org/10.2752/175174414X13871910531665.

Spoel, P., R. Harris, and F. Henwood. 2014. Rhetorics of health citizenship: Exploring vernacular critiques of government's role in supporting healthy living. Journal of Medical Humanities 35 (2): 131-147. https://doi.org/10.1007/s10912-014-9276-6.

Sutherland, J.-A. 2010. Mothering, guilt and shame. Sociology Compass 4 (5): 310-321. https://doi.org/1 0.1111/j.1751-9020.2010.00283.x.

Tanner, J., and S. Timmons. 2000. Backstage in the theatre. Journal of Advanced Nursing 32 (4): 975980. https://doi.org/10.1046/j.1365-2648.2000.t01-1-01564.x.

Vangelisti, A.L. 1994. Family secrets: Forms, functions and correlates. Journal of Social and Personal Relationships 11 (1): 113-135. https://doi.org/10.1177/0265407594111007.

Wajcman, J. 2008. Life in the fast lane? Towards a sociology of technology and time. British Journal of Sociology 59 (1): 59-77. https://doi.org/10.1111/j.1468-4446.2007.00182.x.

Warde, A. 1999. Convenience food: space and timing. British Food Journal 101 (7): 518-527.

Warde, A. 2016. The practice of eating. Cambridge: Polity.

Wills, W., K. Backett-Milburn, M. Roberts, and J. Lawton. 2011. The framing of social class distinctions through family food and eating practices. The Sociological Review 59 (4): 725-740.

Yardley, L. 2000. Dilemmas in qualitative health research. Psychology and Health 15 (2): 215-228. https ://doi.org/10.1080/08870440008400302.

Zelizer, V.A. 1985. Pricing the priceless child: The changing social value of children. New York: Basic Books.

Zivkovic, T., M. Warin, M. Davies, and V. Moore. 2010. In the name of the child: The gendered politics of childhood obesity. Journal of Sociology 46 (4): 375-392. https://doi.org/10.1177/1440783310 384456.

Zobel, E., T. Hansen, P. Rossing, and B. von Scholten. 2016. Global Changes in Food Supply and the Obesity Epidemic. Current obesity reports 5: 449-455. https://doi.org/10.1007/s13679-016-0233-8.

Publisher's Note Springer Nature remains neutral with regard to jurisdictional claims in published maps and institutional affiliations. 